\title{
Propofol Suppressed Hypoxia/Reoxygenation-Induced Apoptosis in HBVSMC by Regulation of the Expression of Bcl-2, Bax, Caspase3, Kir6.1, and p-JNK
}

\author{
Jianhai Zhang, ${ }^{1}$ Yunfei Xia, ${ }^{2}$ Zifeng Xu, ${ }^{3}$ and Xiaoming Deng ${ }^{4}$ \\ ${ }^{1}$ Department of Anesthesiology, Shanghai First People's Hospital, Shanghai Jiao Tong University, Shanghai 200080, China \\ ${ }^{2}$ Department of Anesthesiology, Shanghai International Medical Center, Shanghai 201318, China \\ ${ }^{3}$ Department of Anesthesiology, International Peace Maternal and Child Health Hospital, \\ Shanghai Jiao Tong University, Shanghai 200030, China \\ ${ }^{4}$ Department of Anesthesiology, Changhai Hospital, Second Military Medical University, 168 Changhai Road, \\ Shanghai 200433, China \\ Correspondence should be addressed to Xiaoming Deng; deng_x@yahoo.com
}

Received 16 September 2015; Revised 5 November 2015; Accepted 29 November 2015

Academic Editor: Valentina Parra

Copyright ( 2016 Jianhai Zhang et al. This is an open access article distributed under the Creative Commons Attribution License, which permits unrestricted use, distribution, and reproduction in any medium, provided the original work is properly cited.

Recent studies have found that propofol may protect brain from cerebral ischemic-reperfusion injury. However, the underlying mechanism remains unclear. The effects of propofol were evaluated in HBVSMC after hypoxia/reoxygenation (H/R). Cell viability and levels of SOD, LDH, and MDA were measured. Apoptosis was detected by flow cytometry. The levels of Bax, Bcl-2, Caspase3, Sur2b, Kir6.1, JNK, p-JNK, mTOR, and p-mTOR proteins were measured by western blotting. H/R decreased cell viability and SOD activity and increased LDH leakage and MDA content in HBVSMC, all of which were significantly reversed by propofol. Propofol suppressed the levels of H/R-induced apoptosis. The expression of Bcl-2 and p-mTOR was significantly downregulated and the expression levels of Bax, Caspase3, Kir6.1, and p-JNK were upregulated following H/R injury. The ratio of p-JNK/JNK was increased; however, that of $\mathrm{p}-\mathrm{mTOR} / \mathrm{mTOR}$ decreased correspondingly. The effects on the expression of these proteins were reversed by propofol treatment. SP600125 enhanced and Everolimus attenuated the effect of propofol. These findings suggested that the protective effect of propofol against H/R injury in the HBVSMC was through the inhibition of apoptosis by inducing the expression of Bcl-2 and p-mTOR as well as inhibiting the expression levels of Bax, Caspase3, Kir6.1, and p-JNK.

\section{Introduction}

Transient global cerebral ischemia is one of the major complications of clinical emergencies such as cardiac arrest, drowning, or severe systemic hypotension during a surgical procedure [1]. Ischemic hypoxic brain injury often causes irreversible brain damage. Ischemic stroke accounts for approximately $80 \%$ of all strokes [2] which remains a leading cause of death and adult disability worldwide [3]. Currently, reperfusion of the occluded vessels as soon as possible is the standard treatment for these patients. However, reperfusion may paradoxically exacerbate brain injury, which is called cerebral ischemia/reperfusion (I/R) injury [4]. Ischemic stroke is a serious human health risk and reperfusion plays an important role in cerebral ischemic injury. The extent of brain damage is determined by the severity of primary injury and the intensity of secondary injury cascades that contribute to delayed cellular destruction [5]. Ischemic-reperfusion injury leading to neuronal injury and death includes the release of cytokines and free radicals and induction of inflammation, apoptosis, and excitotoxicity [6]. Apoptosis and oxidative stress have been found to play an important role in the pathogenesis of cerebral injury secondary to ischemia/reperfusion (I/R) $[7,8]$. The striking relationship between apoptosis and brain $I / R$ injury has stimulated considerable interest in the development of antiapoptosis therapies $[9,10]$. Therefore, 
efforts need to be made that not only preserve cerebral blood flow, but also prevent the actual mechanisms that trigger brain damage after I/R injury [11].

Propofol (2,6-disopropylphenol) is an intravenous sedative-hypnotic agent. It is widely used in clinical anesthesia and maintenance of anesthesia or sedation. Recent studies have found that propofol as one of the central inhibitors could reduce brain oxygen consumption and increase intracranial pressure (ICP) and has anticonvulsant, anti-inflammatory, and antioxidant activities. It could also relieve the neurosurgery postoperative damage of brain tissue and blood vessel. However, the mechanism of propofol's protective effect on cerebral hypoxia is not very clear. The object of our study is to explore the mechanism of propofol against cerebral ischemic-reperfusion injury in vitro.

\section{Materials and Methods}

2.1. Cell Culture. Human brain vascular smooth muscle cells (HBVSMC) were purchased from the Cell Bank of Chinese Academy of Sciences (Shanghai, China). The cells were cultured in Dulbecco's modified Eagle medium (DMEM) supplemented with $10 \%$ fetal bovine serum both from GIBCO-Invitrogen (Grand Island, NY) and $1 \%$ penicillin and streptomycin. Cells were maintained at $37^{\circ} \mathrm{C}$ in a humidified atmosphere consisting of $5 \% \mathrm{CO}_{2}$ and $95 \%$ air.

2.2. Hypoxia/Reoxygenation $(H / R)$ Model and Drug Treatment. Cells were exposed to hypoxic conditions (oxygen deprivation, $0.5 \% \mathrm{O}_{2}$ ) for $2 \mathrm{~h}, 4 \mathrm{~h}, 6 \mathrm{~h}$, and $8 \mathrm{~h}$ in culture. After hypoxia, the cells were reoxygenated under normoxic conditions (reoxygenation) for $16 \mathrm{~h}$ in normal medium [12]. Propofol (Fresenius Kabi, China) with different concentrations $(25,50$, and $100 \mu \mathrm{M})$ or propofol combined with SP600125 (Sigma-Aldrich, St. Louis, MO, USA)/Everolimus (Gene Operation Michigan, USA) was added to the cells prior to hypoxia.

2.3. Cell Viability Assay. Cells were plated in 96-well plates at $1 \times 10^{4}$ cells/well. After $24 \mathrm{~h}$ of culture, cells were under hypoxia-oxygenation for several hours or treated with different concentrations of propofol followed by hypoxiaoxygenation or treated with propofol or propofol combined with SP600125/Everolimus for hypoxia-oxygenation and then cultured for $1 \mathrm{~d}, 2 \mathrm{~d}, 3 \mathrm{~d}, 4 \mathrm{~d}, 5 \mathrm{~d}$, and $6 \mathrm{~d}$ in normal conditions, respectively. Cell viability was assessed using Cell Counting Kit-8 (Beyotime, Shanghai, China). $20 \mu \mathrm{L}$ of cell counting assay kit- 8 solution was added daily to three wells per group. After treatment with CCK- 8 at $37^{\circ} \mathrm{C}$ for $2 \mathrm{~h}$, the absorbance at $450 \mathrm{~nm}$ was measured using a microplate reader to quantify the formazan products.

2.4. Measurement of SOD, LDH, and MDA by ELISA. Superoxide dismutase (SOD) activity was assayed with an assay kit purchased from Jiancheng Co. (Nanjing, China). After being frozen and thawed using liquid nitrogen repeatedly, cells were moved to EP tube with hypotonic solution or distilled water. The tube was directly put into liquid nitrogen for 3-5 seconds, followed by $-20^{\circ} \mathrm{C}$ refrigerator (20-30 seconds) immediately, and then thawed at room temperature. The previous process was repeated three times. SOD activity was measured according to the kit's instructions of the manufacturer.

The level of lactate dehydrogenase (LDH) was measured using LDH Activity Assay Kit (Jiancheng Co., Nanjing, China). Culture medium was collected and transferred to a 6-well plate. $\mathrm{LDH}$ reaction mix was added to each well, and the plates were incubated for $30 \mathrm{~min}$ at $37^{\circ} \mathrm{C}$ and for $5 \mathrm{~min}$ at room temperature. The absorbance was read at $450 \mathrm{~nm}$ when the reaction was stopped.

MDA assay was determined by lipid peroxidation MDA Assay Kit (Beyotime, Shanghai, China). Cells were lysed and reacted with thiobarbituric acid (TBA). The product has an absorbance peak at $532 \mathrm{~nm}$. MDA was calculated by using a standard curve according to the manufacturer's data sheet. The results were expressed as micromole per gram protein ( $\mu \mathrm{mol} / \mathrm{g}$ protein).

2.5. Apoptosis Assay by Flow Cytometry. Cells after H/R and treatment with propofol $(50 \mu \mathrm{M})$ or SP600125/Everolimus were harvested by brief trypsinization and centrifugation (at $170 \times \mathrm{g}$ ), washed in ice-cold PBS, and fixed in 70\% ethanol for 2 hours at $-20^{\circ} \mathrm{C}$. Apoptosis was detected by double-staining with annexin $\mathrm{V}$ conjugated to fluorescein isothiocyanate and propidium iodide (Bender Medsystems). Ten thousand cells per sample were acquired in a FACScan flow cytometer and the proportions of labeled cells were analyzed using Paint-AGate software (Becton Dickinson).

2.6. Western Blot Analysis. Cells after H/R and treatment with propofol or SP600125/Everolimus were harvested and washed twice with cold PBS and subsequently lysed in $1 \mathrm{x}$ SDS-PAGE loading buffer $(120 \mu \mathrm{L}$ per well of 6 -well plate). The samples of cell lysis were heated to $95-100^{\circ} \mathrm{C}$ for $10 \mathrm{~min}$ followed by cooling on ice and centrifuged at $10,960 \times \mathrm{g}$ for $1 \mathrm{~min}$ at $4^{\circ} \mathrm{C}$. The supernatant was run on $10 \%$ SDS-PAGE gel and transferred electrophoretically to a polyvinylidene fluoride membrane (PVDF, Millipore, Shanghai, China). The blots were blocked for $1 \mathrm{~h}$ at $25^{\circ} \mathrm{C}$ with $5 \%$ skim milk in Tris-buffered saline containing Tween 20 (TBST) followed by incubation with primary antibodies against Tubulin (Abcam), Bax (Proteintech), Bcl-2 (Abcam), Caspase3 (CST), Sur2b (CST), Kir6.1 (Santa Cruz Biotechnology), JNK (CST), p-JNK (CST), mTOR (CST), and p-mTOR (CST) overnight at $4^{\circ} \mathrm{C}$. After being washed with TBST, the membranes were incubated with proper secondary antibodies (Beyotime, Shanghai, China). Blots were then incubated and visualized with enhanced chemiluminescence (ECL, Thermo Scientific, Shanghai, China). The results were normalized to Tubulin to correct for loading.

2.7. Data Analysis. Results are presented as means \pm standard deviations (SD) of three samples. Significant differences in the mean values were evaluated by Student's unpaired $t$-test. Places needing multiple comparisons were evaluated by oneway ANOVA with Bonferroni correction. $P$ value of 0.05 or less was considered to be statistically significant. 


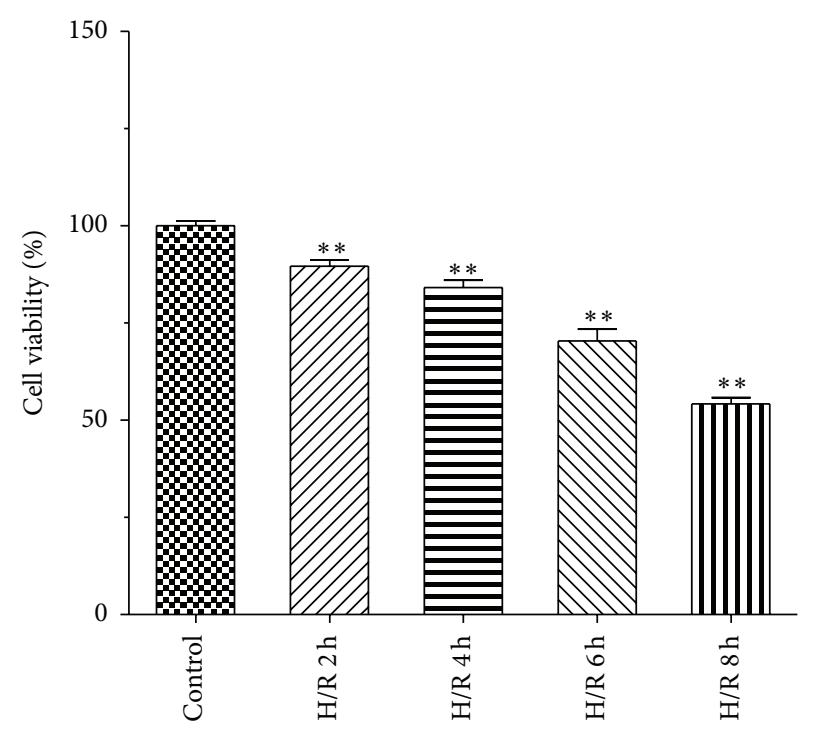

(a)

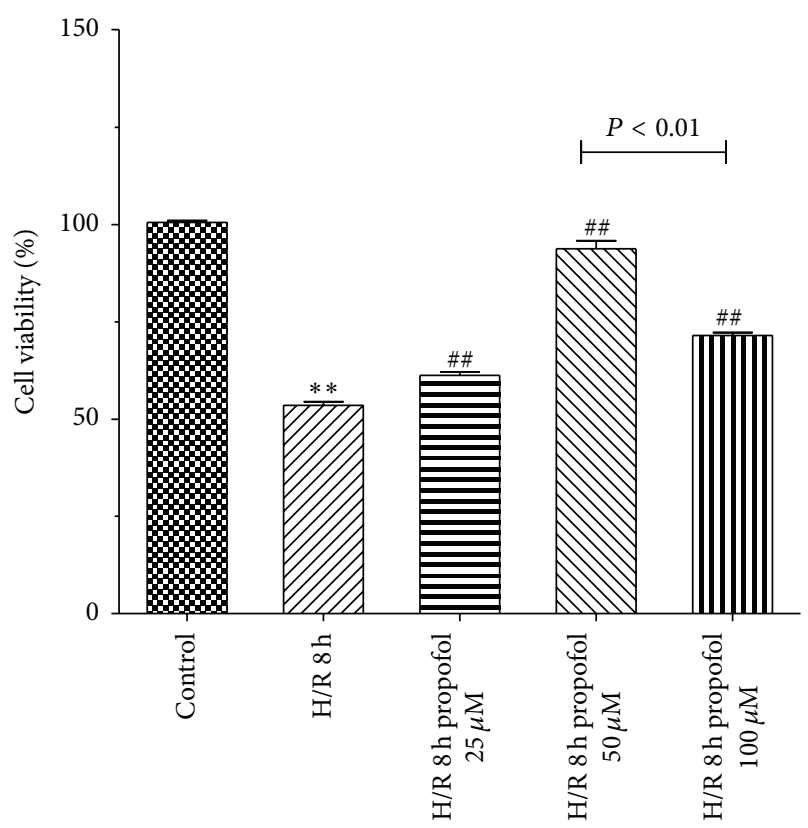

(b)

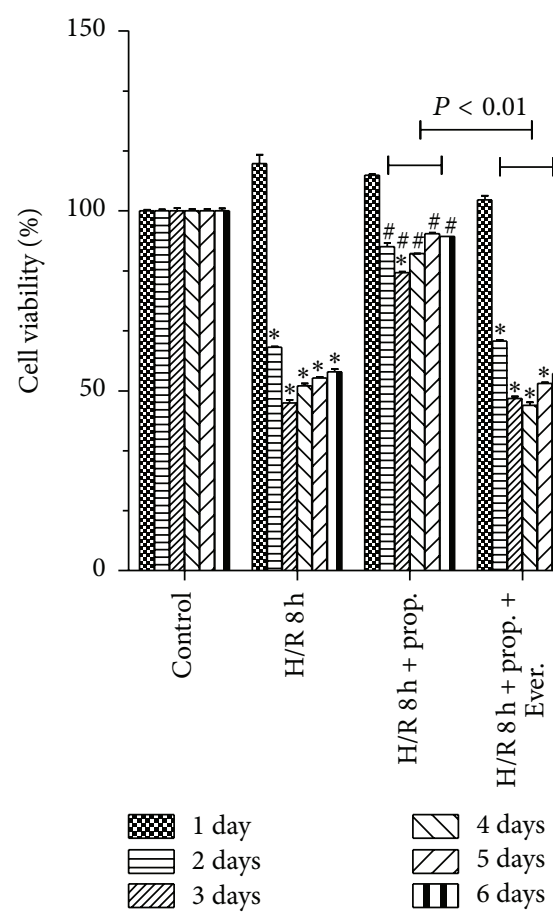

(c)

FIGURE 1: Protective effects of propofol on H/R-induced cytotoxicity HBVSMC. (a) Cell viability was assessed by CCK8 assay. Cells were exposed to hypoxic conditions. Hypoxia/reoxygenation (H/R) for 2 h, 4 h, 6 h, and 8 h. The viability of control group was defined as $100 \%$. (b) Propofol $(25,50$, and $100 \mu \mathrm{M})$ was adopted during the entire ischemia/reperfusion phase. Cell viability was assessed. (c) HBVSMC after H/R and treatment with propofol or propofol combined with SP600125 (SP)/Everolimus (Ever.) were cultured for 1d, $2 \mathrm{~d}, 3 \mathrm{~d}, 4 \mathrm{~d}, 5 \mathrm{~d}$, and $6 \mathrm{~d}$ in normal conditions. Cell viability was assessed. Mean $\pm \mathrm{SD}, n=3 .{ }^{*} P<0.05$ versus control. ${ }^{*} P<0.05$ versus $\mathrm{H} / \mathrm{R}$ group without drugs.

\section{Results}

3.1. Propofol Inhibited Cell Viability Decrease. Compared with control group, cell viability was significantly decreased during $\mathrm{H} / \mathrm{R}$ insult in model group (Figure 1(a)). Compared with model group, propofol treatments significantly inhibited the decrease of cell viability (Figure 1(b)). Propofol inhibited the cell damage in a dose-dependent manner induced by $\mathrm{H} / \mathrm{R}$. However, $100 \mu \mathrm{M}$ of propofol has damaging effects on HBVSMC under oxidative stress conditions. Figure 1(c) 


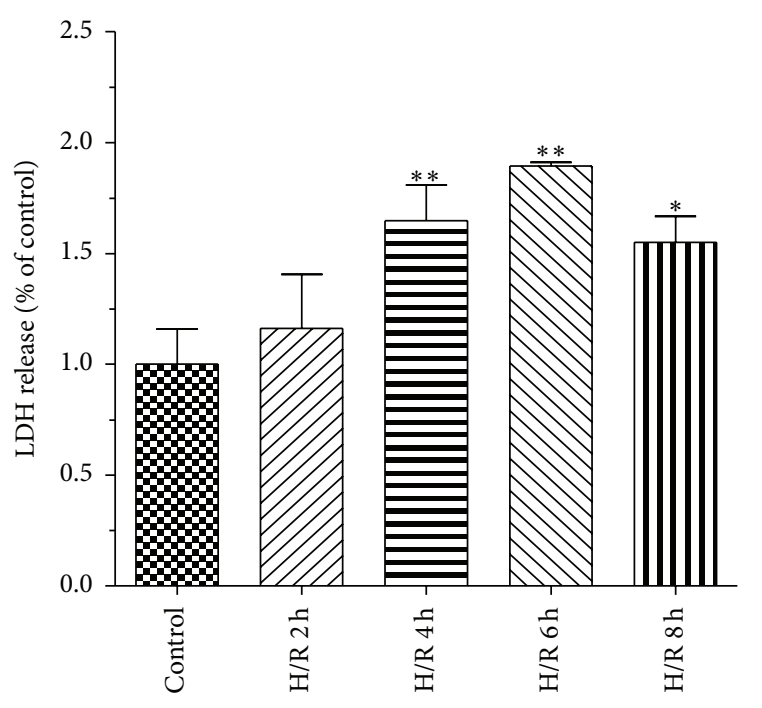

(a)

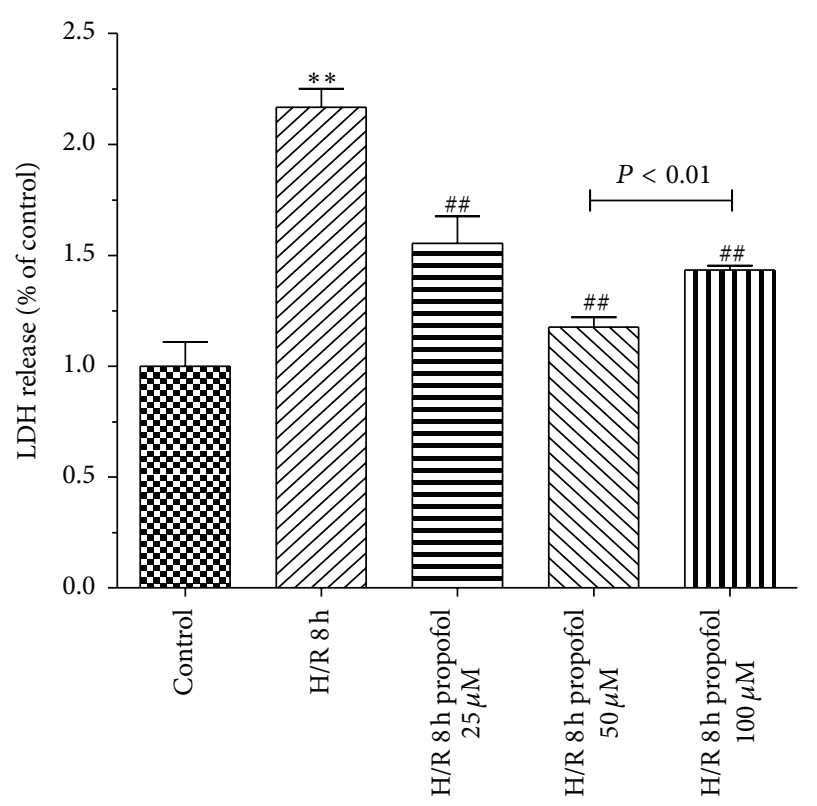

(b)

FIGURE 2: Effects of propofol on LDH leakage in HBVSMC. (a) Cells were exposed to hypoxic conditions. Hypoxia/reoxygenation (H/R) for $2 \mathrm{~h}, 4 \mathrm{~h}, 6 \mathrm{~h}$, and $8 \mathrm{~h}$. (b) Propofol $(25,50$, and $100 \mu \mathrm{M})$ was adopted during the entire ischemia/reperfusion phase. Mean \pm SD, $n=3$. ${ }^{*} P<0.05,{ }^{* *} P<0.01$ versus control; ${ }^{\#} P<0.05,{ }^{\# \#} P<0.01$ versus $\mathrm{H} / \mathrm{R}$ group without drugs.

shows the viability of HBVSMC after addition of propofol combined with SP600125/Everolimus to the cells prior to hypoxia. Everolimus, a mTOR inhibitor, blocked the effect of propofol on the cells viability induced by H/R. Cell viability of propofol-SP600125 group was higher than that of propofol group $(P<0.01)$. The effect of SP600125, a JNK inhibitor, as reported [13] was significantly attenuated by Everolimus.

\subsection{Propofol Decreased LDH and MDA Levels Induced by $H / R$} in HBVSMC. $\mathrm{H} / \mathrm{R}$ is known to induce oxidative stress. Cell death was assessed based on the amount of lactate dehydrogenase (LDH). Compared with model group, propofol treatments significantly inhibited LDH leakage induced by H/R (Figures 2(a) and 2(b)).

MDA, which is a marker of lipid peroxidation, was measured to evaluate the oxidative injury of H/R. In our study, $H / R$ obviously elevated intracellular MDA levels compared with control. Compared with H/R group, propofol obviously inhibited MDA levels (Figures 3(a) and 3(b)). Moreover, the levels of MDA were measured as an indicator of lipid peroxidation. The results showed that propofol $(25,50$, and $100 \mu \mathrm{M})$ could inhibit lipid peroxidation injury in cells. The result was consistent with previous report about propofol decreasing the levels of MDA $[14,15]$.

\subsection{Propofol Increased the Activities of SOD in H/R Group.} Superoxide dismutase (SOD) can protect cells from damage by elimination of oxygen free radicals. SOD is one of the endogenous antioxidative enzymes that protect against ROSinduced damage [15]. In H/R model group, the activities of SOD were significantly decreased compared with control group. Propofol $(25,50$, and $100 \mu \mathrm{M})$ group significantly increased SOD activity (Figures $4(\mathrm{a})$ and $4(\mathrm{~b})$ ).

3.4. HBVSMC Apoptosis. Stimulation of HBVSMC by H/R resulted in a marked significant increase in apoptotic index (Figure 5). Propofol decreased the rate of apoptotic cells. SP600125 decreased H/R-induced apoptotic cell death. On the other hand, Everolimus significantly increased cell apoptosis induced by H/R. Propofol combined with SP600125 further attenuated cell apoptosis induced by H/R. Propofol attenuated but did not prevent apoptotic cell death induced by Everolimus in combination with $\mathrm{H} / \mathrm{R}$.

3.5. Protein Expression of Bax, Bcl-2, Caspase3, Sur2b, Kir6.1, JNK, $p$-JNK, mTOR, and $p$-mTOR. To investigate the effect of propofol on the expression of HBVSMC hypoxia/reoxygenation injury-related proteins and the mechanism involved, we measured the levels of Bax, Bcl-2, Caspase3, Sur2b, Kir6.1, JNK, p-JNK, mTOR, and p-mTOR proteins. As shown in Figure 6, the protein expressions of Bax, Caspase3, Kir6.1, and p-JNK in H/R group were 1.30, 1.25, 1.18, and 3.27 times more than that in control group, which were attenuated by the treatment of propofol. The protein expressions of p-JNK and the ratio of p-JNK/JNK were especially high. Addition of Everolimus further decreased the protein expression of Bax, Caspase3, Kir6.1, and p-JNK, which was reversed by SP600125 treatment. The protein expressions of Bcl-2 and p-mTOR were obviously decreased while the ratio of $\mathrm{p}-\mathrm{mTOR} / \mathrm{mTOR}$ was decreased correspondingly in HBVSMC subjected to $\mathrm{H} / \mathrm{R}$ stimulation as compared with 


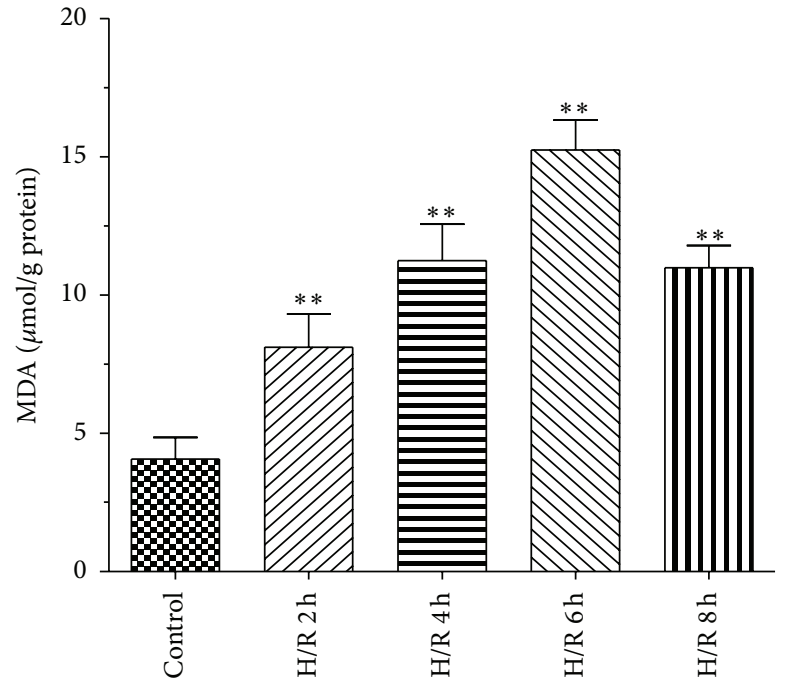

(a)

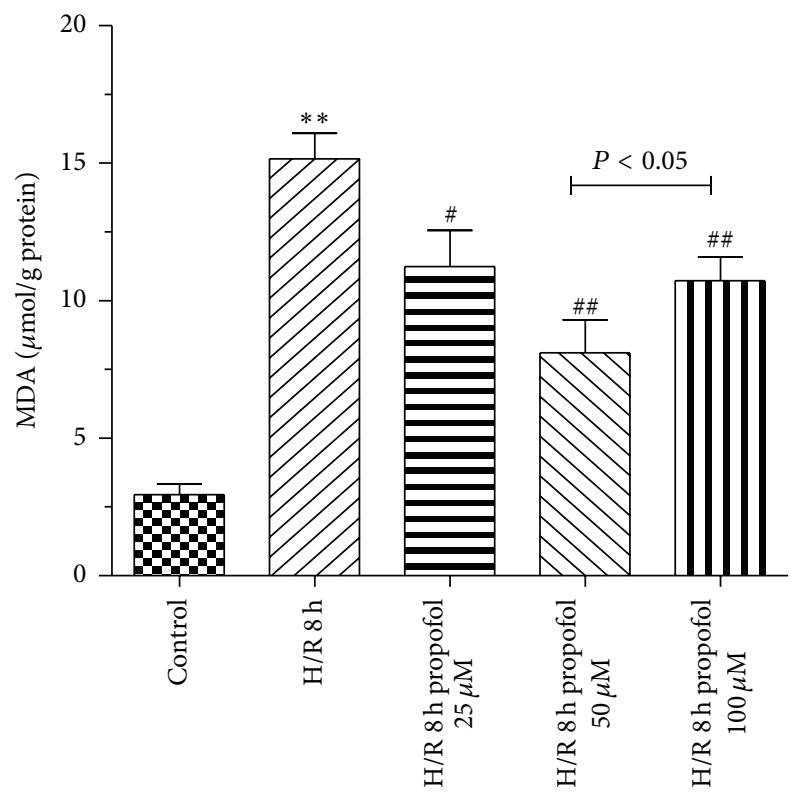

(b)

Figure 3: Effects of propofol on MDA in HBVSMC. (a) Cells were exposed to hypoxic conditions. Hypoxia/reoxygenation (H/R) for $2 \mathrm{~h}, 4 \mathrm{~h}$, $6 \mathrm{~h}$, and $8 \mathrm{~h}$. (b) Propofol $(25,50$, and $100 \mu \mathrm{M})$ was adopted during the entire ischemia/reperfusion phase. Mean $\pm \mathrm{SD}, n=3 .{ }^{*} P<0.05$, ${ }^{* *} P<0.01$ versus control; ${ }^{\#} P<0.05,{ }^{\# \#} P<0.01$ versus $\mathrm{H} / \mathrm{R}$ group without drugs.

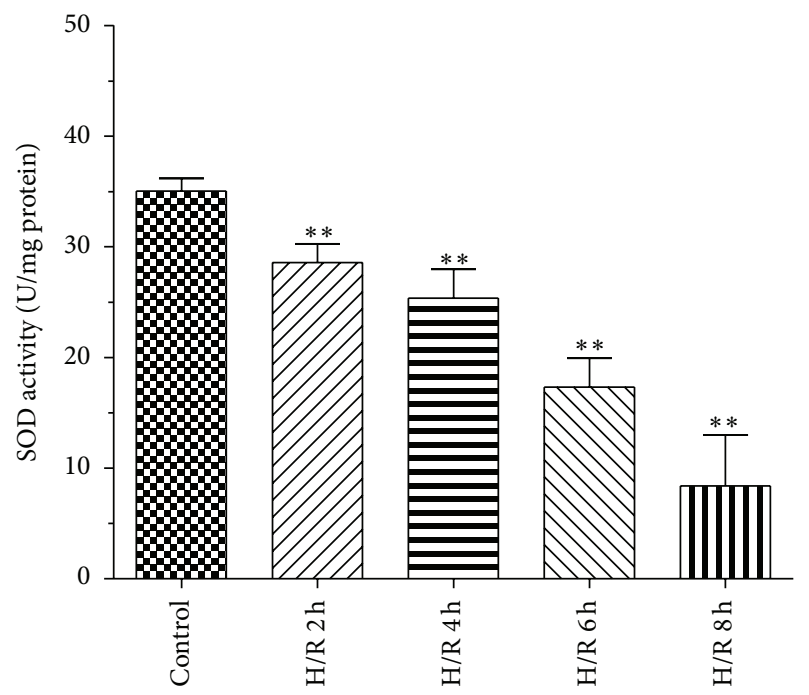

(a)

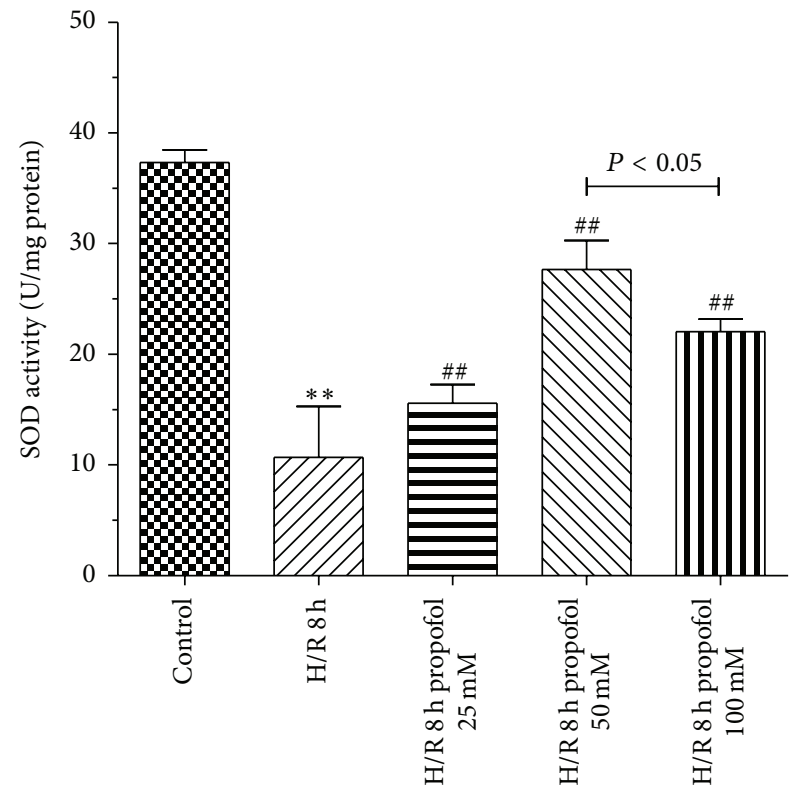

(b)

FIGURE 4: Effects of propofol on SOD activity in HBVSMC. (a) Cells were exposed to hypoxic conditions. Hypoxia/reoxygenation (H/R) for $2 \mathrm{~h}, 4 \mathrm{~h}, 6 \mathrm{~h}$, and $8 \mathrm{~h}$. (b) Propofol $(25,50$, and $100 \mu \mathrm{M})$ was adopted during the entire ischemia/reperfusion phase. Mean \pm SD, $n=3$. ${ }^{*} P<0.05,{ }^{* *} P<0.01$ versus control; ${ }^{\#} P<0.05,{ }^{\# \#} P<0.01$ versus $H / R$ group without drugs.

those of control group, which were attenuated by the treatment of propofol. Propofol combined with Everolimus further increased the protein expression of Bcl-2 and p-mTOR, which was reversed by SP600125 treatment. Furthermore, there was no significant difference in the protein expressions of Sur2b, JNK, and mTOR between H/R and control group.

\section{Discussion}

In the present study, we used human brain vascular smooth muscle cell (HBVSMC) to establish $\mathrm{H} / \mathrm{R}$ model in vitro to investigate the effect of propofol in the treatment of ischemia/reperfusion (I/R) injury. Vascular smooth muscle 


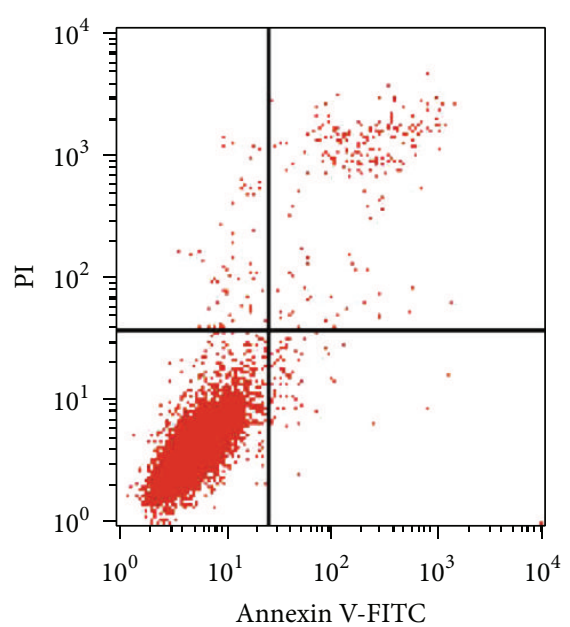

(a)

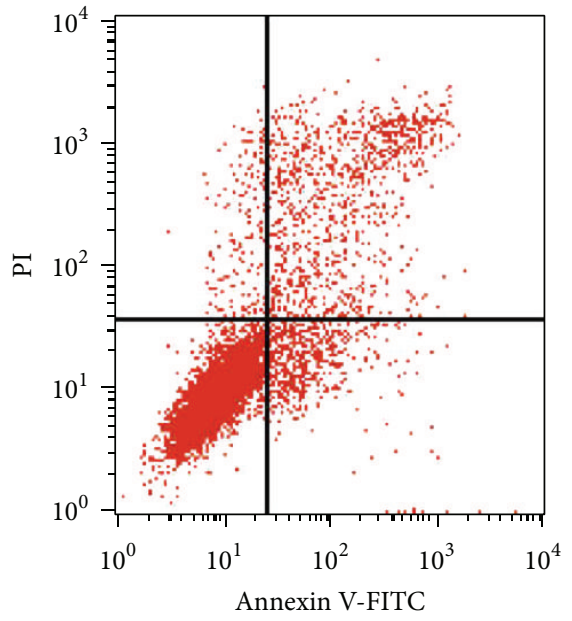

(d)

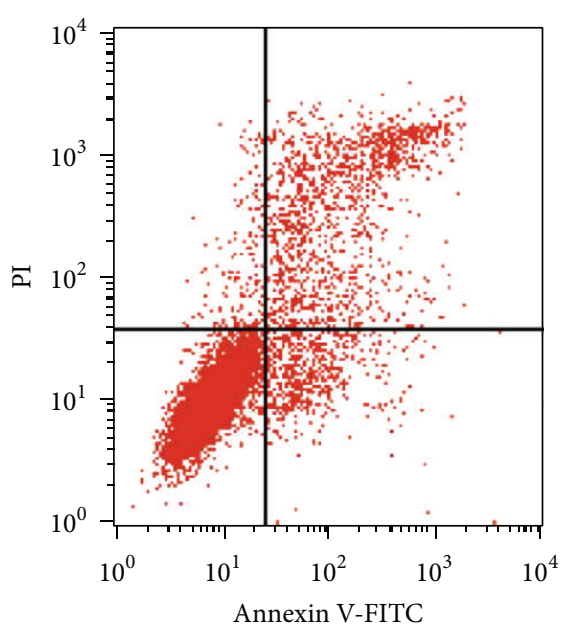

(b)

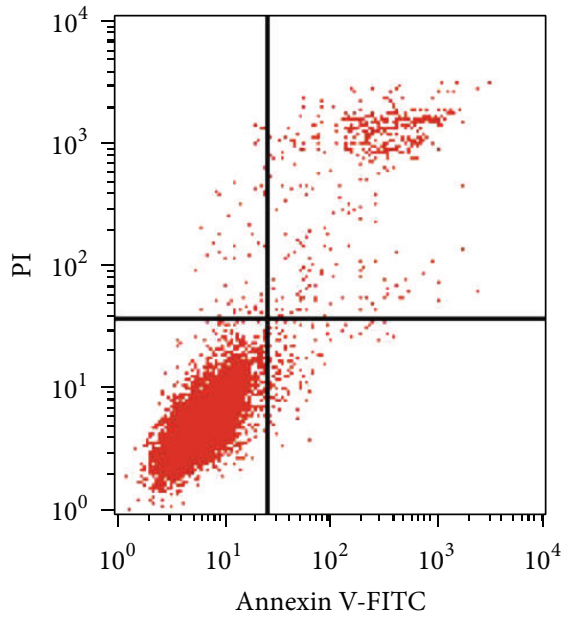

(e)

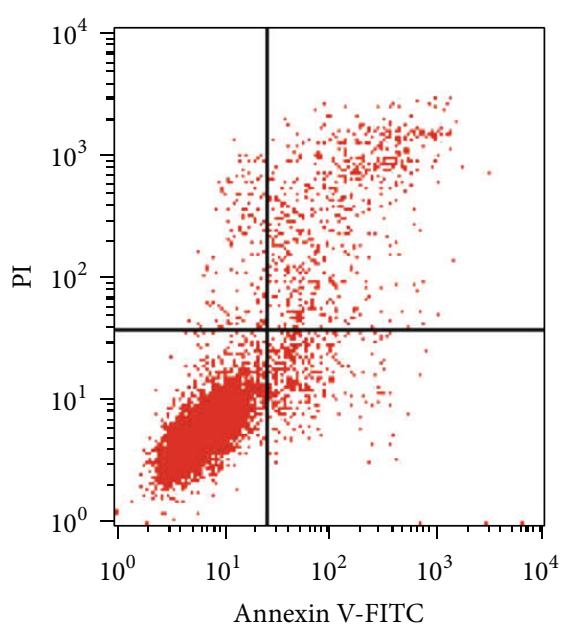

(c)

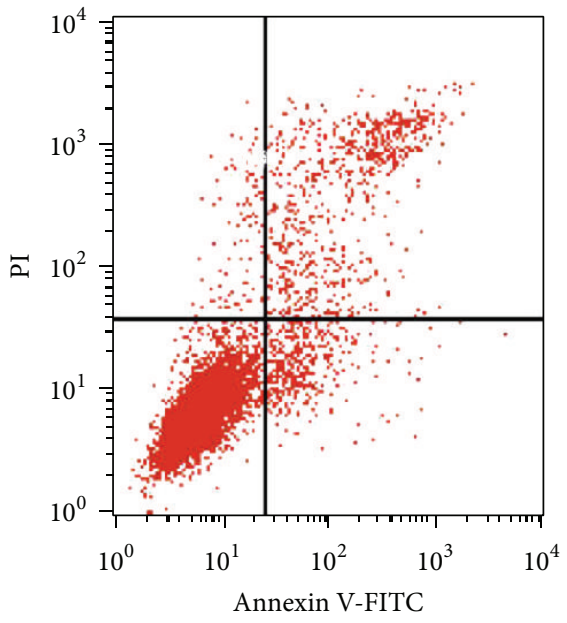

(f)

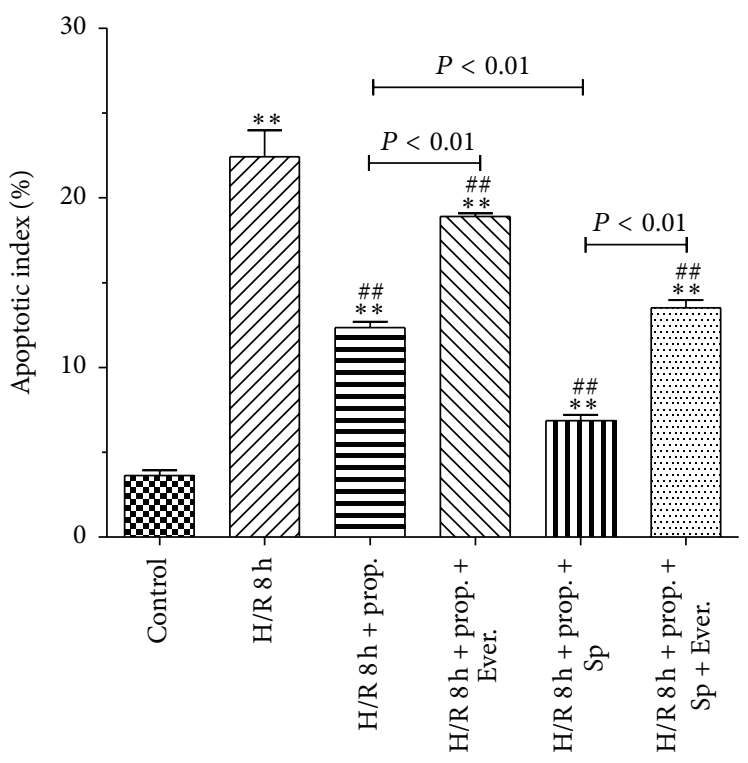

(g)

FIGURE 5: Effects of propofol on apoptosis of HBVSMC. (a)-(f) Representative figures of flow cytometry results and rate of apoptosis measured by flow cytometry (g). Flow cytometric analysis was carried out as described in Materials and Methods. Primary cultured HBVSMC were either not treated (control) or treated with propofol $(50 \mu \mathrm{M})$ or propofol $(50 \mu \mathrm{M})$ combined with SP600125 (SP)/Everolimus (Ever.). Mean \pm $\mathrm{SD}, n=3 .{ }^{*} P<0.05,{ }^{* *} P<0.01$ versus control; ${ }^{*} P<0.05,{ }^{\# \#} P<0.01$ versus $\mathrm{H} / \mathrm{R}$ group without drugs. 


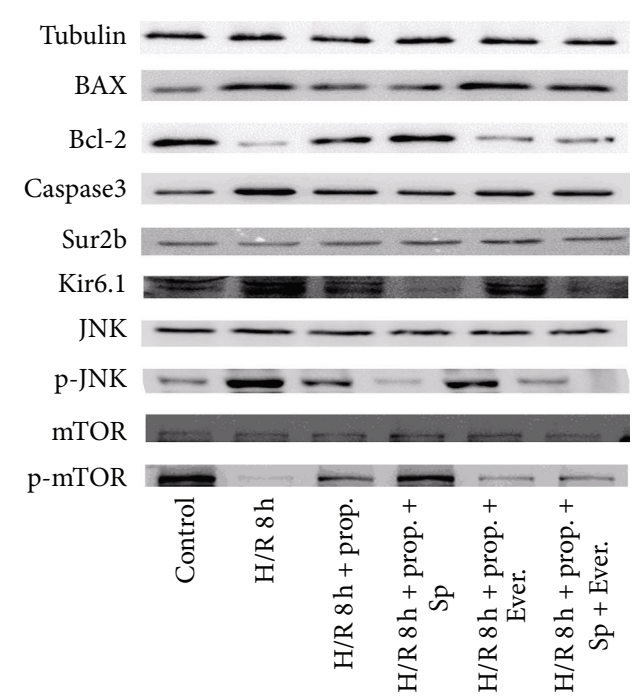

(a)

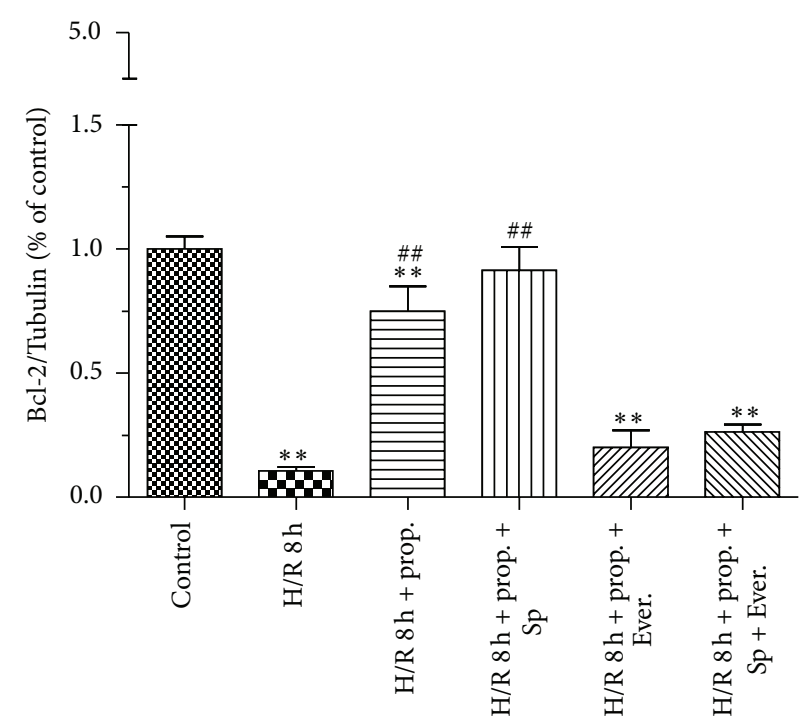

(c)

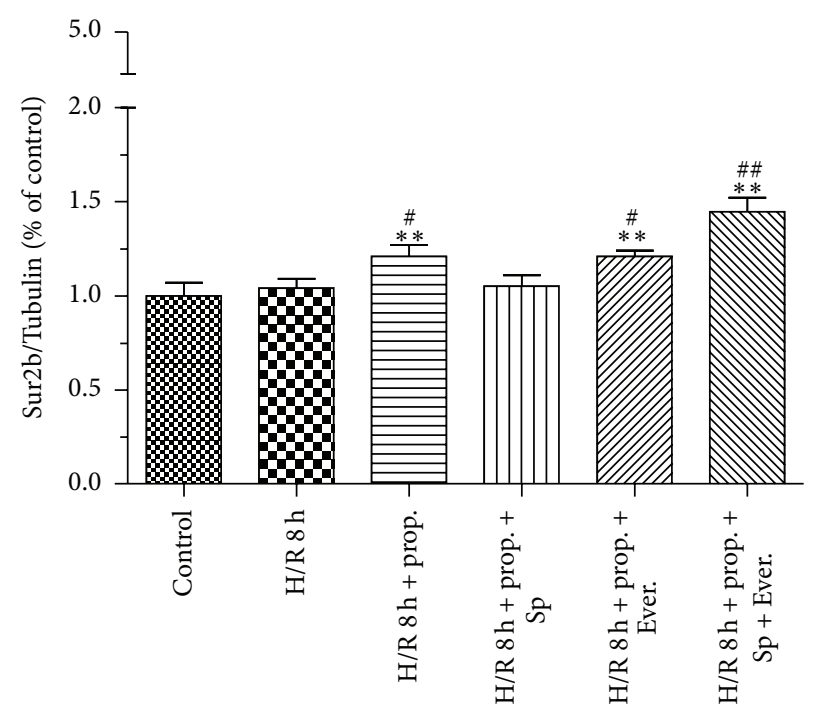

(e)

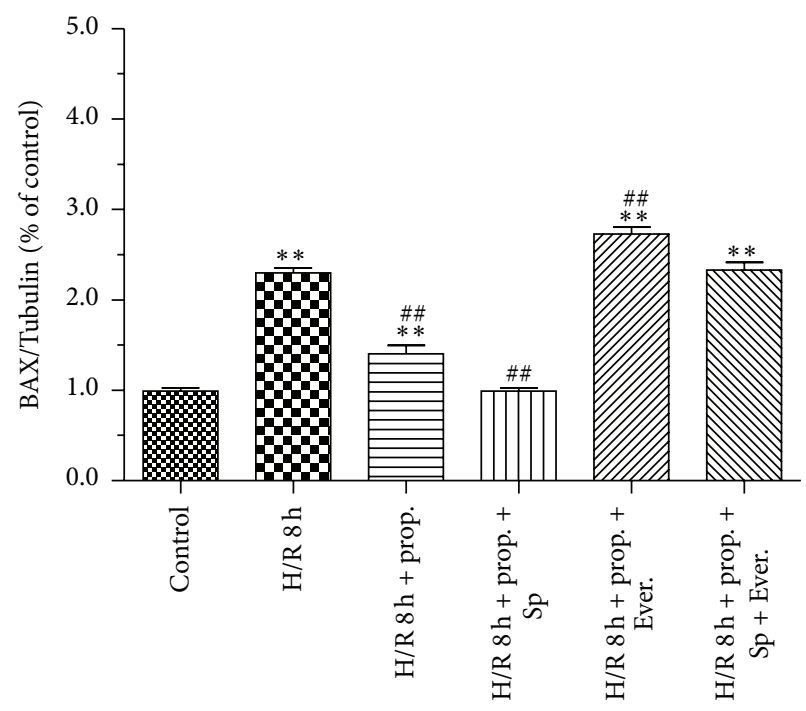

(b)

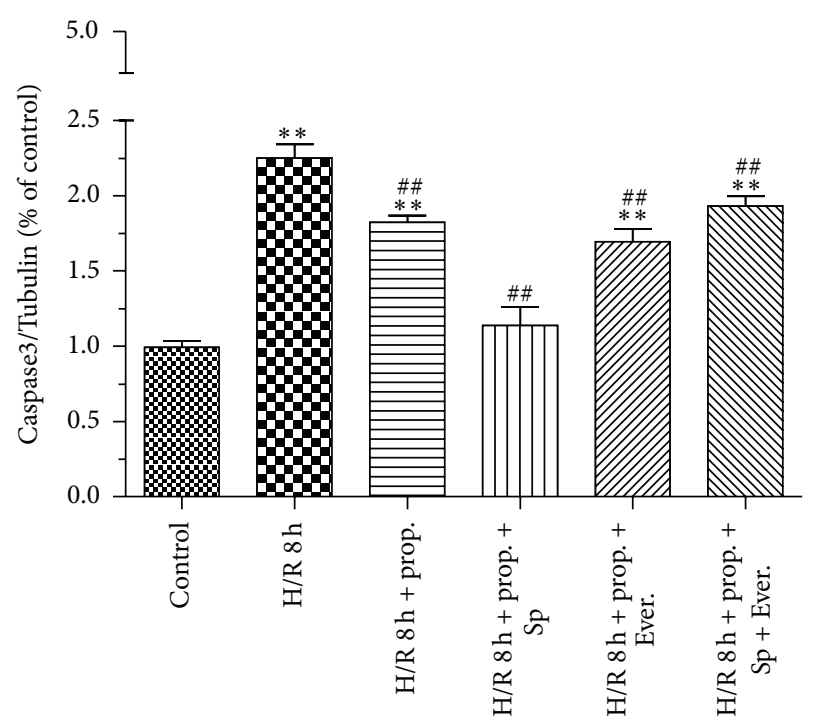

(d)

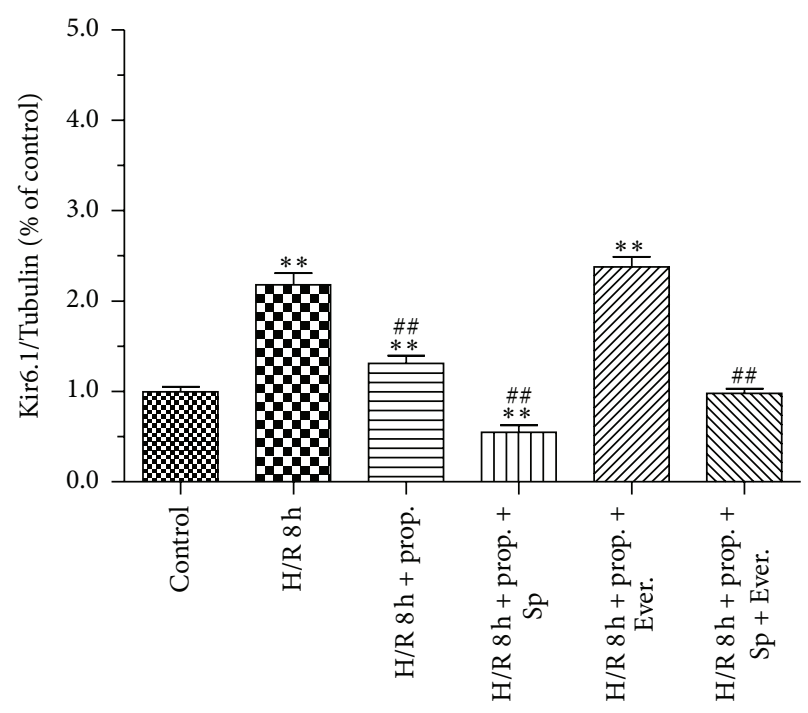

(f)

Figure 6: Continued. 

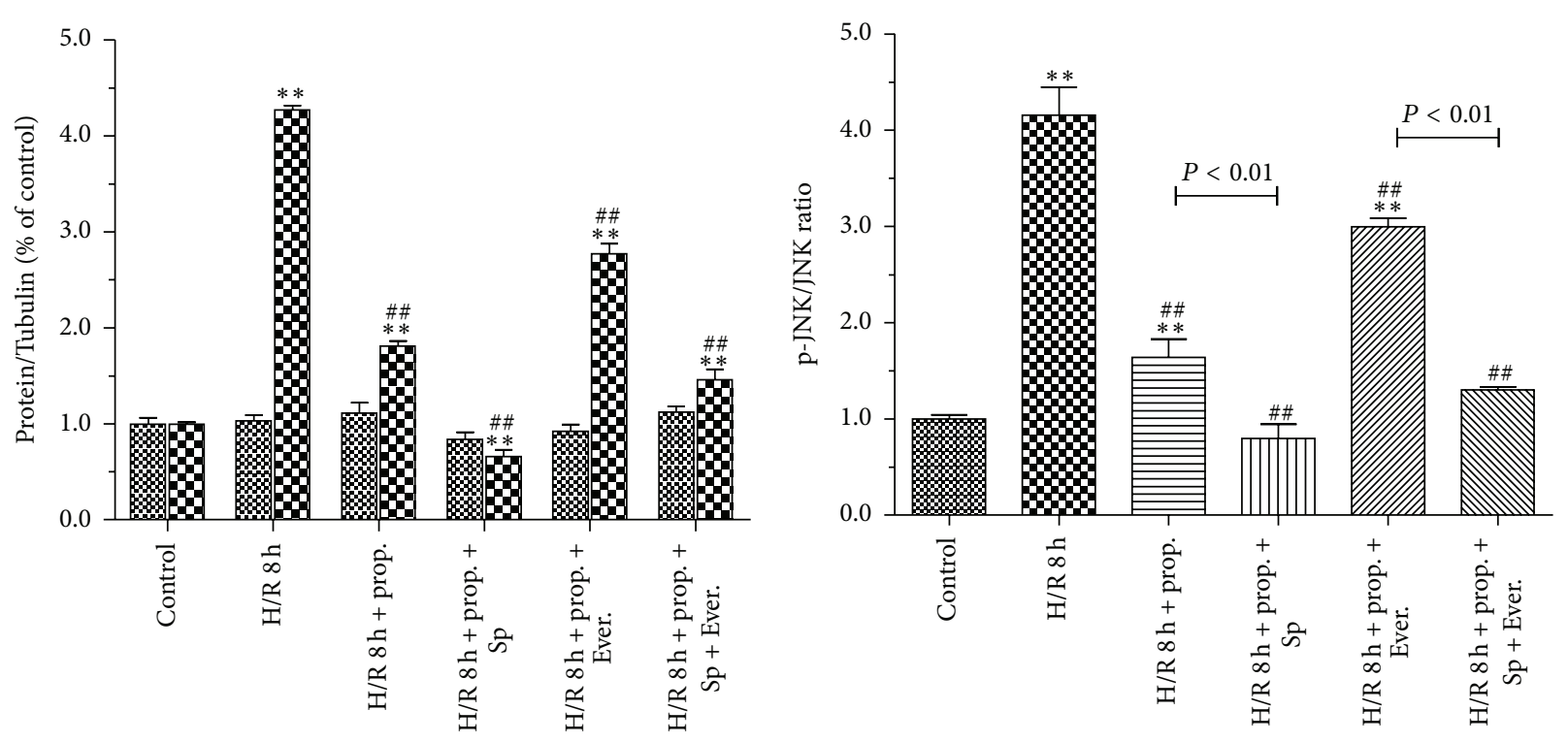

\% JNK/Tubulin

D-JNK/Tubulin

(g)

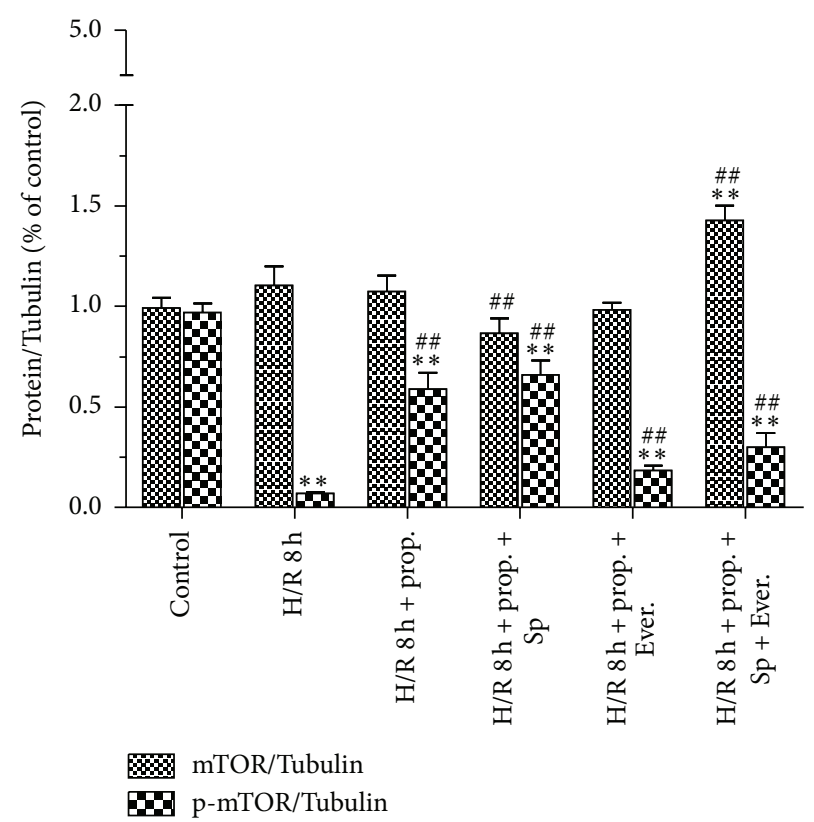

(h)

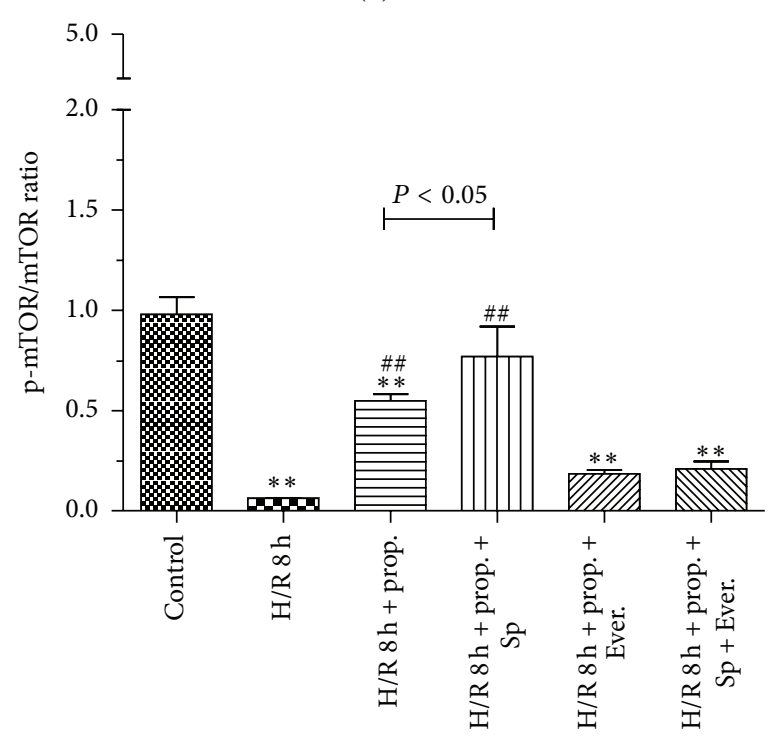

(j)

Figure 6: The effects of propofol $(50 \mu \mathrm{M})$ on Bax, Bcl-2, Caspase3, Sur2b, Kir6.1, JNK, p-JNK, mTOR, and p-mTOR expression in HBVSMC. (a)-(f), (g), and (i) represent the levels of Bax, Bcl-2, Caspase3, Sur2b, Kir6.1, JNK, p-JNK, mTOR, and p-mTOR which were determined by western blotting and Tubulin was used as positive control. (h) and (j) show the ratio of p-JNK/JNK and p-mTOR/mTOR, respectively. HBVSMC cells were either not treated (control) or treated with propofol (50 $\mu \mathrm{M})$ or propofol $(50 \mu \mathrm{M})$ combined with SP600125 (Sp)/Everolimus (Ever.). Mean $\pm \mathrm{SD}, n=4 .{ }^{*} P<0.05,{ }^{* *} P<0.01$ versus control; ${ }^{\#} P<0.05,{ }^{\# \#} P<0.01$ versus H/R group without drugs.

cell is the cellular substrate of most significant arterial diseases [16]. One of the crucial anomalies responsible for the development of essential vascular diseases is the increased growth potential of vascular smooth muscle cells. Smooth muscle cells proliferation in atherosclerosis was of particular concern as a high proportion of cardiac and central nervous system death is believed to result from spasm of damaged vessels [16]. Cerebral vasculature plays a central role in the pathogenesis of cardiovascular diseases, such as stroke $[17,18]$, and in the initiation of inflammation after cerebral ischemia, which is a key determinant in stroke outcome $[18,19]$. A substantial source of reactive oxygen species in the site of ischemic lesion is also the immune response [17]. Vascular smooth muscle cell, smooth muscle actin (SMA), 
was one of the blood brain barrier components [20, 21]. Experimental results have shown that ischemia followed by reperfusion results in blood brain barrier disruption [22$24]$ and leakage of immune cells into the damaged brain tissue [25-27]. I/R injury is the tissue injury, structure damage, and dysfunction of organs due to the reperfusion after ischemia. As a secondary injury after primary brain injury, I/R injury is an important factor that contributes to the brain injury. Besides the significant decrease of brain function, it can cause secondary injury of heart, liver, and kidney, being seriously harmful to the whole body [2830]. The incidence rate of $I / R$ injury has also increased as the natural disasters and traffic accidents increase in recent years [31]. With the rapid development of medical technology, there have been several methods to decrease the risk of I/R injury, such as reducing the operation time, improving the operation method, preadaptation to ischemia, and increasing blood supply for brain; however, there is no obvious change of biochemical factors inducing $I / R$ injury [32]. In recent years, numerous studies found that the excellent effect of propofol on anti-inflammation and antioxidation could inhibit the overrelease of oxygen radical under stress status, which was expected to reduce the risk of biochemical factor mediated I/R injury [33-35]. And several studies have found that propofol had effects on the prevention and treatment of I/R injury; however, further exploration about the mechanism is still needed $[36,37]$. As previously reported $[38,39]$, the change of protein physicochemical property, structure, and function is the important reason which causes occurrence and development of $I / R$ injury. Therefore, we explored I/R injury-related protein expression and mechanism expected to decrease the incidence rate of $I / R$ injury.

We examined protective effects and mechanism of propofol against H/R-induced injury in HBVSMC in the presence or absence of SP600125/Everolimus. Hypoxia/reoxygenation injury was assessed by using the cell viability, SOD activity, LDH leakage, and MDA content. Results showed that cell viability and SOD activity decreased with prolonged H/R injury. LDH leakage and MDA content were the highest at $6 \mathrm{~h}$. The most possible reason was that enhanced resistance to $\mathrm{H} / \mathrm{R}$ and cells self-recovery from injury increased at $8 \mathrm{~h}$ [40]. In order to explore the effect of propofol against H/R injury, we selected $8 \mathrm{~h}$ after hypoxia for further research. In our study, the data demonstrated that treatment with propofol reduced cell death, LDH leakage, and MDA content and increased SOD activity in a dose-dependent way, which indicate that propofol has a strong protective effect against oxidative stress induced injury in HBVSMC. However, cell death, LDH leakage, and MDA content increased and SOD activity decreased when the concentration of propofol was $100 \mu \mathrm{M}$, which suggested that $100 \mu \mathrm{M}$ propofol exhibited cytotoxicity in vitro in HBVSMC. Propofol is highly lipophilic and therefore is concentrated in lipid-rich tissues such as brain $[41,42]$. Studies in animals [42] and humans [41, 43, 44] indicate that the measured/predicted brain concentration of propofol during maintenance of surgical anesthesia is above $22 \mu \mathrm{M}$ and as high as $73 \mu \mathrm{M}$. The $25-50 \mu \mathrm{M}$ concentration range used in our experiments is therefore within the range of concentrations that exist in the human brain during anesthesia; however, $100 \mu \mathrm{M}$ is higher than the upper limit of the concentration range. As previously reported [45], overdose of propofol $(140 \mu \mathrm{M})$ causes GSK-3 $\beta$-mediated macrophage apoptosis; however, the attenuated effect of propofol with low dose $(5.6-56 \mu \mathrm{M})$ has been shown. Liu et al. [46] reported that $100 \mu \mathrm{M}$ of propofol and/or higher doses (e.g., 300 and $600 \mu \mathrm{M})$ decreased rat neural stem cell viability. Another previous report also showed that $50 \mu \mathrm{M}$ of propofol has damaging effects on $\mathrm{H} 9 \mathrm{c} 2$ cells under oxidative stress conditions [47]. The damaging effects of propofol $(100 \mu \mathrm{M})$ on HBVSMC cells under oxidative stress conditions may be similar to propofol effects on macrophage, rat neural stem cell, and H9c2 cells. Therefore, we used $50 \mu \mathrm{M}$ propofol for further study. Everolimus, as a mTOR inhibitor, blocked the effect of propofol on the cells viability induced by H/R significantly compared with JNK inhibitor SP600125. Propofol combined with SP600125 further decreased the apoptosis of HBVSMC which suggested that SP600125 enhanced the protective effect of propofol against H/R injury. Propofol combined with Everolimus further increased the apoptosis of HBVSMC and the index of the apoptosis of HBVSMC in group treated with propofol combined with SP600125 and Everolimus was between propofol combined with SP600125 and propofol combined with Everolimus. Decreased cell viability was a result of increased cell apoptosis. In our study, the result of cell apoptosis was consistent with that of cell viability. According to previous reports, activation of the JNK signaling cascade and expression of Bcl-2, Bax, and Caspase 3 leads to apoptosis during H/R [40, 48]; mTOR function was one of the "master switch" proteins in cells to modulate metabolism, cell cycle, and apoptosis [49]; Sur and Kir subunits are able to associate to form potassium channels $[50,51]$, which associate with apoptosis. We measured the levels of Bax, Bcl-2, Caspase3, Sur2b, Kir6.1, JNK, p-JNK, mTOR, and p-mTOR proteins to investigate the mechanism of propofol. Results of our study suggested that the protective effect of propofol against $\mathrm{H} / \mathrm{R}$ injury in the HBVSMC was through the inhibition of apoptosis by inhibiting the expression levels of Bax, Caspase3, Kir6.1, and p-JNK and inducing the expression of $\mathrm{Bcl}-2$ and p-mTOR.

\section{Conclusion}

In summary, the results from the present study indicated that the protective effect of propofol against $H / R$ injury in the HBVSMC was through the inhibition of apoptosis by inhibiting the expression levels of Bax, Caspase3, Kir6.1, and p-JNK and inducing the expression of Bcl-2 and p-mTOR. Propofol may offer a promising therapeutic approach for the treatment of HBVSMC injury resulting from ischemia/reperfusion (I/R).

\section{Conflict of Interests}

All authors declare that they have no conflict of interests related to this study. 


\section{Acknowledgments}

This study was supported by a grant from the Shanghai Municipal Commission of Health and Family Planning (no. 20134188) and Shanghai First People's Hospital (no. 12B20).

\section{References}

[1] K. Chu, B. Yin, J. Wang et al., "Inhibition of P2X7 receptor ameliorates transient global cerebral ischemia/reperfusion injury via modulating inflammatory responses in the rat hippocampus," Journal of Neuroinflammation, vol. 9, article 69, 2012.

[2] V. L. Feigin, C. M. M. Lawes, D. A. Bennett, and C. S. Anderson, "Stroke epidemiology: a review of population-based studies of incidence, prevalence, and case-fatality in the late 20th century," The Lancet Neurology, vol. 2, no. 1, pp. 43-53, 2003.

[3] S. J. Yu, J. R. Kim, C. K. Lee et al., "Gastrodia elata blume and an active component, p-hydroxybenzyl alcohol reduce focal ischemic brain injury through antioxidant related gene expressions," Biological and Pharmaceutical Bulletin, vol. 28, no. 6, pp. 1016-1020, 2005.

[4] A. V. Alexandrov, "Current and future recanalization strategies for acute ischemic stroke," Journal of Internal Medicine, vol. 267, no. 2, pp. 209-219, 2010.

[5] M. Li, X. Zhang, L. Cui et al., "The neuroprotection of oxymatrine in cerebral ischemia/reperfusion is related to nuclear factor erythroid 2-related factor 2 (nrf2)-mediated antioxidant response: role of nrf2 and hemeoxygenase-1 expression," Biological and Pharmaceutical Bulletin, vol. 34, no. 5, pp. 595-601, 2011.

[6] S. Kuroda and B. K. Siesjö, "Reperfusion damage following focal ischemia: pathophysiology and therapeutic windows," Clinical Neuroscience, vol. 4, no. 4, pp. 199-212, 1997.

[7] J. Qi, Z. Y. Hong, H. Xin, and Y. Z. Zhu, "Neuroprotective effects of leonurine on ischemia/reperfusion-induced mitochondrial dysfunctions in rat cerebral cortex," Biological and Pharmaceutical Bulletin, vol. 33, no. 12, pp. 1958-1964, 2010.

[8] J. Zhao, S. Yu, W. Zheng et al., "Curcumin improves outcomes and attenuates focal cerebral ischemic injury via antiapoptotic mechanisms in rats," Neurochemical Research, vol. 35, no. 3, pp. 374-379, 2010.

[9] J.-P. Yang, H.-J. Liu, H. Yang, and P.-Y. Feng, “Therapeutic time window for the neuroprotective effects of NGF when administered after focal cerebral ischemia," Neurological Sciences, vol. 32, no. 3, pp. 433-441, 2011.

[10] Q. Li, R. Zhang, Y.-L. Guo, and Y.-W. Mei, "Effect of neuregulin on apoptosis and expressions of STAT3 and GFAP in rats following cerebral ischemic reperfusion," Journal of Molecular Neuroscience, vol. 37, no. 1, pp. 67-73, 2009.

[11] D. Amantea, G. Nappi, G. Bernardi, G. Bagetta, and M. T. Corasaniti, "Post-ischemic brain damage: pathophysiology and role of inflammatory mediators," The FEBS Journal, vol. 276, no. 1, pp. 13-26, 2009.

[12] S. Lee, K. Kim, Y. H. Kim et al., "Preventive role of propofol in hypoxia/reoxygenation-induced apoptotic H9c2 rat cardiac myoblast cell death," Molecular Medicine Reports, vol. 4, no. 2, pp. 351-356, 2011.

[13] W. Wang, L. Shi, Y. Xie et al., "SP600125, a new JNK inhibitor, protects dopaminergic neurons in the MPTP model of Parkinson's disease," Neuroscience Research, vol. 48, no. 2, pp. 195-202, 2004.
[14] M. Ucar, U. Ozgül, A. Polat et al., "Comparison of antioxidant effects of isoflurane and propofol in patients undergoing donor hepatectomy," Transplantation Proceedings, vol. 47, no. 2, pp. 469-472, 2015.

[15] M. Akın, H. Ayoglu, D. Okyay et al., "Effects of various anesthesia maintenance on serum levels of selenium, copper, zinc, iron and antioxidant capacity," Brazilian Journal of Anesthesiology (English Edition), vol. 65, no. 1, pp. 51-60, 2015.

[16] S. M. Schwartz, G. R. Campbell, and J. H. Campbell, "Replication of smooth muscle cells in vascular disease," Circulation Research, vol. 58, no. 4, pp. 427-444, 1986.

[17] K. L. Zuloaga and R. J. Gonzales, "Dihydrotestosterone attenuates hypoxia inducible factor-lalpha and cyclooxygenase-2 in cerebral arteries during hypoxia or hypoxia with glucose deprivation," The American Journal of Physiology-Heart and Circulatory Physiology, vol. 301, no. 5, pp. H1882-H1890, 2011.

[18] G. J. del Zoppo and T. Mabuchi, "Cerebral microvessel responses to focal ischemia," Journal of Cerebral Blood Flow and Metabolism, vol. 23, no. 8, pp. 879-894, 2003.

[19] H. C. A. Emsley and P. J. Tyrrell, "Inflammation and infection in clinical stroke," Journal of Cerebral Blood Flow and Metabolism, vol. 22, no. 12, pp. 1399-1419, 2002.

[20] E. Norsted, B. Gömüç, and B. Meister, "Protein components of the blood-brain barrier (BBB) in the mediobasal hypothalamus," Journal of Chemical Neuroanatomy, vol. 36, no. 2, pp. 107-121, 2008.

[21] N. Maolood and B. Meister, "Protein components of the bloodbrain barrier (BBB) in the brainstem area postrema-nucleus tractus solitarius region," Journal of Chemical Neuroanatomy, vol. 37, no. 3, pp. 182-195, 2009.

[22] J. Dobbin, H. A. Crockard, and R. Ross-Russell, "Transient blood-brain barrier permeability following profound temporary global ischaemia: an experimental study using 14C-AIB," Journal of Cerebral Blood Flow and Metabolism, vol. 9, no. 1, pp. 71-78, 1989.

[23] J. I. Sage, R. L. Van Uitert, and T. E. Duffy, "Early changes in blood brain barrier permeability to small molecules after transient cerebral ischemia," Stroke, vol. 15, no. 1, pp. 46-50, 1984.

[24] G.-Y. Yang and A. L. Betz, "Reperfusion-induced injury to the blood-brain barrier after middle cerebral artery occlusion in rats," Stroke, vol. 25, no. 8, pp. 1658-1665, 1994.

[25] M. Campanella, C. Sciorati, G. Tarozzo, and M. Beltramo, "Flow cytometric analysis of inflammatory cells in ischemic rat brain," Stroke, vol. 33, no. 2, pp. 586-592, 2002.

[26] J. M. Schwab, R. Beschorner, R. Meyermann, F. Gözalan, and H. J. Schluesener, "Persistent accumulation of cyclooxygenase1 -expressing microglial cells and macrophages and transient upregulation by endothelium in human brain injury," Journal of Neurosurgery, vol. 96, no. 5, pp. 892-899, 2002.

[27] M.-Y. Lee, Y.-H. Kuan, H.-Y. Chen et al., "Intravenous administration of melatonin reduces the intracerebral cellular inflammatory response following transient focal cerebral ischemia in rats," Journal of Pineal Research, vol. 42, no. 3, pp. 297-309, 2007.

[28] R. A. Kloner, K. Przyklenk, and P. Whittaker, "Deleterious effects of oxygen radicals in ischemia/reperfusion. Resolved and unresolved issues," Circulation, vol. 80, no. 5, pp. 1115-1127, 1989.

[29] Y.-C. Yoo, K.-J. Yoo, B. J. Lim, J.-H. Jun, J.-K. Shim, and Y.-L. Kwak, "Propofol attenuates renal ischemia-reperfusion injury aggravated by hyperglycemia," Journal of Surgical Research, vol. 183, no. 2, pp. 783-791, 2013. 
[30] Z. Xu, M. Dong, L. Fang, R. Dong, and S. Li, "The effect of propofol on the expression of rabbit ischemia reperfusion injury-related proteins," Cell Biochemistry and Biophysics, vol. 71, no. 2, pp. 1165-1170, 2015.

[31] A. Nakajima, M. Tsuji, M. Inagaki et al., "Neuroprotective effects of propofol on ER stress-mediated apoptosis in neuroblastoma SH-SY5Y cells," European Journal of Pharmacology, vol. 725, no. 1, pp. 47-54, 2014.

[32] X. Shen, G. Zhao, R. Wang, T. Liu, and L. Liu, "Protective effect of propofol and resveratrol pretreatment against hepatocyte apoptosis in rats with hepatic ischemia-reperfusion injury," Nan Fang Yi Ke Da Xue Xue Bao, vol. 33, no. 1, pp. 80-85, 2013.

[33] D. Özkan, T. Akkaya, A. Yalcindag et al., "Propofol sedation in total knee replacement: effects on oxidative stress and ischemiareperfusion damage," Der Anaesthesist, vol. 62, no. 7, pp. 537542,2013

[34] C. Lin, H. Sui, J. Gu et al., "Effect and mechanism of propofol on myocardial ischemia reperfusion injury in type 2 diabetic rats," Microvascular Research, vol. 90, pp. 162-168, 2013.

[35] C. Liang, J. Cang, H. Wang, and Z. Xue, "Propofol attenuates cerebral ischemia/reperfusion injury partially using heme oxygenase-1," Journal of Neurosurgical Anesthesiology, vol. 25, no. 3, pp. 311-316, 2013.

[36] C. Li, M. Xu, Y. Wu, Y.-S. Li, W.-Q. Huang, and K.-X. Liu, "Limb remote ischemic preconditioning attenuates lung injury after pulmonary resection under propofol-remifentanil anesthesia: a randomized controlled study," Anesthesiology, vol. 121, no. 2, pp. 249-259, 2014

[37] E. Kottenberg, J. Musiolik, M. Thielmann, H. Jakob, J. Peters, and G. Heusch, "Interference of propofol with signal transducer and activator of transcription 5 activation and cardioprotection by remote ischemic preconditioning during coronary artery bypass grafting," Journal of Thoracic and Cardiovascular Surgery, vol. 147, no. 1, pp. 376-382, 2014.

[38] J. H. Lee, D. J. Joo, J. M. Kim, J. H. Park, Y. S. Kim, and B.-N. Koo, "Preconditioning effects of the anesthetic administered to the donor on grafted kidney function in living donor kidney transplantation recipients," Minerva Anestesiologica, vol. 79, no. 5, pp. 504-514, 2013.

[39] J. H. Lee, H. S. Cui, S. K. Shin et al., "Effect of propofol post-treatment on blood-brain barrier integrity and cerebral edema after transient cerebral ischemia in rats," Neurochemical Research, vol. 38, no. 11, pp. 2276-2286, 2013.

[40] C. Li and R. M. Jackson, "Reactive species mechanisms of cellular hypoxia-reoxygenation injury," American Journal of Physiology-Cell Physiology, vol. 282, no. 2, pp. C227-C241, 2002.

[41] S. Kahraman, S. L. Zup, M. M. McCarthy, and G. Fiskum, "GABAergic mechanism of propofol toxicity in immature neurons," Journal of Neurosurgical Anesthesiology, vol. 20, no. 4, pp. 233-240, 2008.

[42] P. L. Riu, G. Riu, C. Testa et al., "Disposition of propofol between red blood cells, plasma, brain and cerebrospinal fluid in rabbits," European Journal of Anaesthesiology, vol. 17, no. 1, pp. 18-22, 2000.

[43] D. A. Ferreira, C. S. Nunes, L. Antunes, F. Lobo, and P. Amorim, "Practical aspects of the use of target controlled infusion with remifentanil in neurosurgical patients: predicted cerebral concentrations at intubation, incision and extubation," Acta Anaesthesiologica Belgica, vol. 57, no. 3, pp. 265-270, 2006.

[44] G. L. Ludbrook, V. Elizabeth, and A. M. Lam, "Propofol: relation between brain concentrations, electroencephalogram, middle cerebral artery blood flow velocity, and cerebral oxygen extraction during induction of anesthesia," Anesthesiology, vol. 97, no. 6, pp. 1363-1370, 2002.

[45] C. H. Hsing, C. L. Chen, W. C. Lin, C. F. Lin, and L. G. Ng, "Propofol treatment inhibits constitutive apoptosis in human primary neutrophils and granulocyte-differentiated human HL60 cells," PLoS ONE, vol. 10, no. 6, Article ID e0129693, 2015.

[46] F. Liu, S. W. Rainosek, N. Sadovova et al., "Protective effect of acetyl-L-carnitine on propofol-induced toxicity in embryonic neural stem cells," NeuroToxicology, vol. 42, pp. 49-57, 2014.

[47] D. Zhao, Q. Li, Q. Huang et al., "Cardioprotective effect of propofol against oxygen glucose deprivation and reperfusion injury in H9c2 cells," Oxidative Medicine and Cellular Longevity, vol. 2015, Article ID 184938, 8 pages, 2015.

[48] J. M. McCord, "Oxygen-derived free radicals in postischemic tissue injury," The New England Journal of Medicine, vol. 312, no. 3, pp. 159-163, 1985.

[49] M. Castedo, K. F. Ferri, and G. Kroemer, "Mammalian target of rapamycin (mTOR): pro- and anti-apoptotic," Cell Death and Differentiation, vol. 9, no. 2, pp. 99-100, 2002.

[50] L. Aguilar-Bryan, C. G. Nichols, S. W. Wechsler et al., "Cloning of the beta cell high-affinity sulfonylurea receptor: a regulator of insulin secretion," Science, vol. 268, no. 5209, pp. 423-426, 1995.

[51] C. G. Nichols, "KATP channels as molecular sensors of cellular metabolism," Nature, vol. 440, no. 7083, pp. 470-476, 2006. 


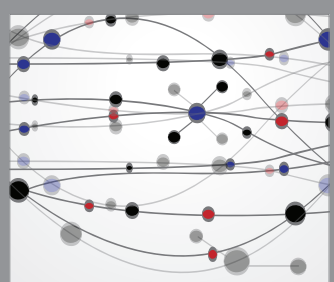

The Scientific World Journal
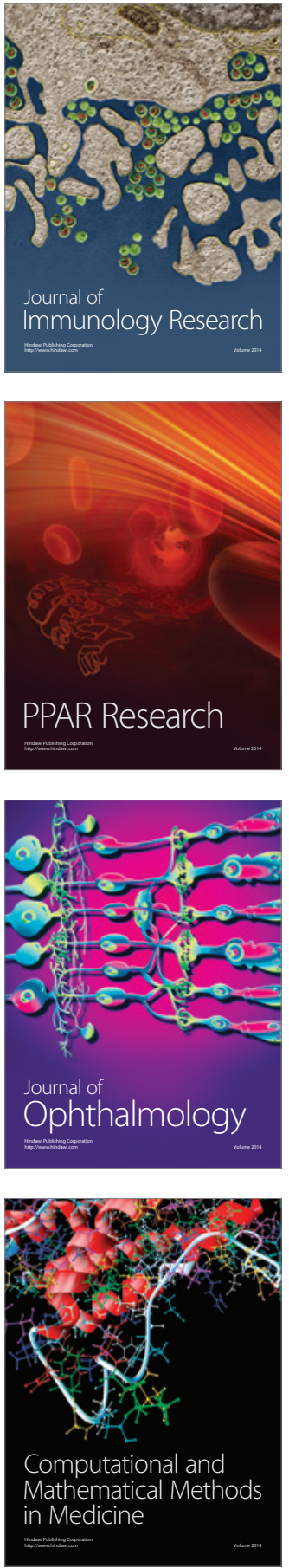

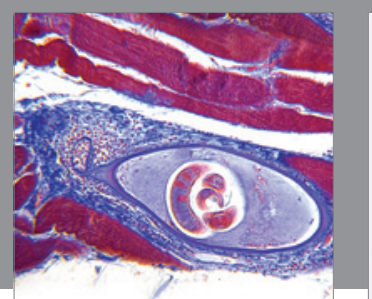

Gastroenterology Research and Practice

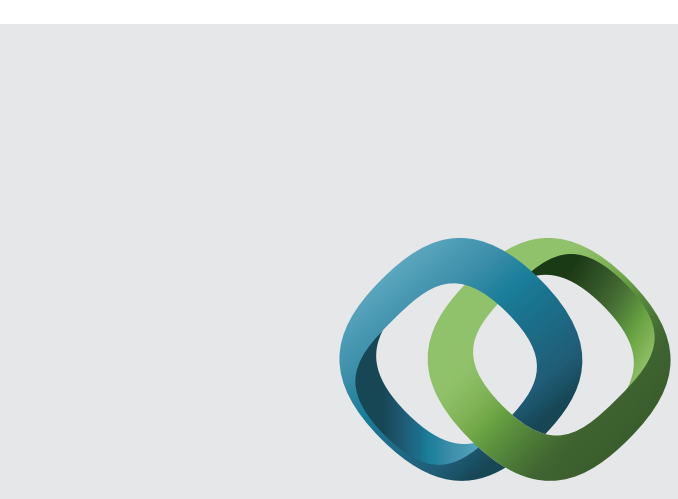

\section{Hindawi}

Submit your manuscripts at

http://www.hindawi.com
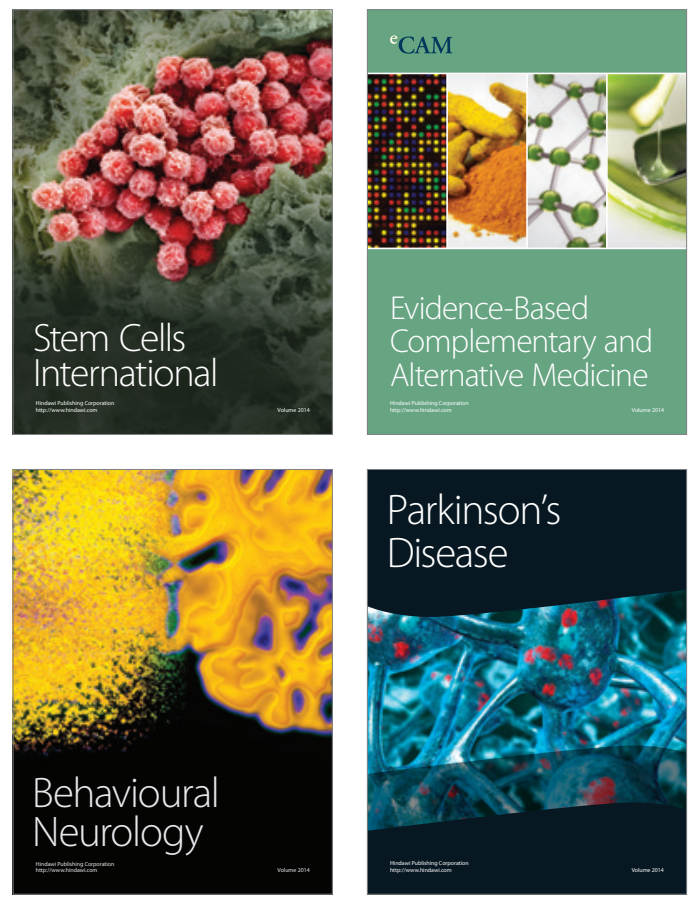
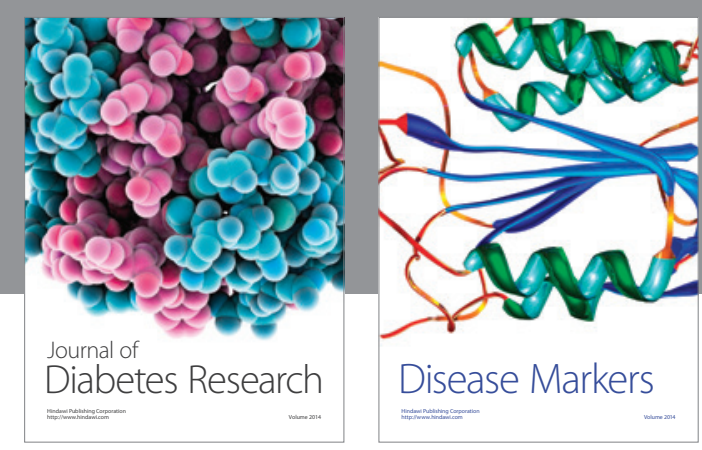

Disease Markers
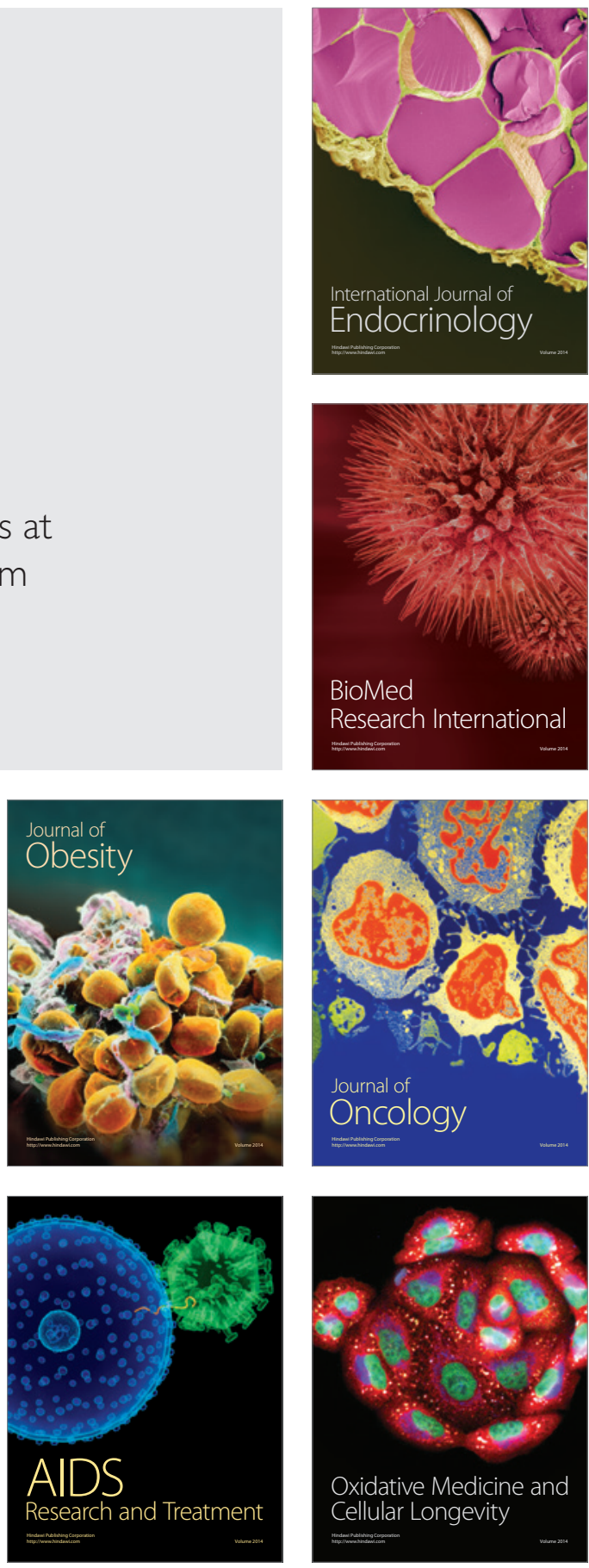